\title{
Argumentação e estruturas gramaticais contrastivas: atividade prática de resgate de conhecimentos prévios usando ambientes virtuais de aprendizagem
}

\author{
Manoel Francisco Guaranha* \\ Ana Lúcia Tinoco Cabral**
}

\section{Resumo}

Este trabalho apresenta uma atividade prática de leitura de uma crônica de Lima Barreto, Queixa de defunto, como resultado de pesquisas na área da linguística que ensejaram a construção de uma situação de aprendizagem significativa a partir do resgate dos conhecimentos prévios dos estudantes, da sensibilização deles para as diferentes estruturas gramaticais contrastivas, adversativas e concessivas, de modo que possam compreender, na prática, a diferença e a função dessas estruturas no processo argumentativo. Nesse sentido, o artigo apresenta um exercício de leitura que prevê o uso de ambientes virtuais de aprendizagem para mobilizar os conhecimentos prévios do aprendiz para que ele possa compreender a dinâmica dos articuladores na construção de estratégias argumentativas; possa sistematizá-la e internalizá-la de modo mais eficiente.
Essa prática de ensino mostra a importância dos conectores na construção de textos escritos com competente orientação argumentativa.

Palavras-chave: Leitura. Escrita. Argumentação. Gramática. Tecnologias da informação e comunicação.
* Doutor em Letras pela USP/SP. Docente do Programa de Pós-Graduação em Linguística da Universidade Cruzeiro do Sul - UnicSul/SP e professor Pleno da Fatec - Faculdade de Tecnologia do Estado de São - São Paulo. E-mail: m-guaranha@uol.com.br

** Doutora em Língua Portuguesa pela PUCSP, com Pós-Doutorado em Linguística Teórica pela EHESS. Professora Titular da Universidade Cruzeiro do Sul UnicSul, docente do Mestrado em Linguística. E-mail: mailto:altinococabral@gmail.com; altinococabral@ gmail.com

Data de submissão: set. 2015 - Data de aceite: nov. 2015 http://dx.doi.org/10.5335/rdes.v11ii2.5379 


\section{Considerações iniciais}

Este trabalho parte do princípio de que o processo de ensino e aprendizagem de leitura e escrita são indissociáveis e que, nesse processo, o estudo das regras gramaticais só tem algum sentido se for feito de modo incidental. A prática de se ensinar ao aprendiz nomenclaturas que incluem as categorias morfológicas, sintáticas e semânticas na esperança de que ele se valha dessa lista de nomes de ferramentas para aplicá-las no momento da leitura ou da produção de textos tem se mostrado ineficaz. Essa metodologia pauta-se em uma concepção ultrapassada de linguagem, vista como um instrumento de comunicação. Atualmente, a linguagem deve ser considerada sob a perspectiva enunciativa. Segundo Benveniste:

[...] a comparação da linguagem com um instrumento [...] deve encher-nos de respeito, como toda noção simplista a respeito de linguagem. A picareta, a flecha, a roda não estão na natureza. São fabricações. A linguagem está na natureza do homem que não a fabricou. [....] Não atingimos nunca o homem separado da linguagem e não o vemos nunca inventando-a. [...] É um homem falando com outro homem, e a linguagem ensina a própria definição do homem (2005, p. 285).

Nesse sentido, a palavra como produto da subjetividade humana atualiza a linguagem e assegura a comunicação por meio da produção de textos orais e escritos. Se concebermos o texto como uma máquina de produção de sentido, só para aquele que efetivamente dá manutenção nessa máquina é que serve o conhecimento taxonômico das peças, ou seja, aos professores e estudiosos da língua, no caso de estabelecermos uma analogia entre essa máquina e o motor textual, a linguagem verbal escrita. Ainda assim, é preciso compreender que esse conhecimento se constrói a posteriori, a partir de estudos das produções verbais em seus respectivos contextos. Àqueles que, como motoristas de um carro, apenas o põem em funcionamento para dele extrair movimento, sentido no caso do motor textual, interessa mais compreender as propriedades dessas peças e de como são úteis no resultado da operação, bem como seu valor dentro da engrenagem verbal na expressão de um querer dizer subjetivo daquele que comunica.

Desse modo, assumimos com Lyons (1990) que o uso da linguagem é como um jogo cujas regras aprendemos jogando. Com efeito, o domínio de uma língua não se dá pelo aprendizado de regras prescritivas que regem o seu uso "correto", ou listas de nomenclaturas dos fenômenos gramaticais. Adquire-se o domínio de uma língua participando de uma multiplicidade de usos de linguagem diferentes, inseridos em contextos variados que implicam convenções sociais específicas.

No século XXI, podemos pensar que uma forma de aproximar os estudantes da compreensão relativamente ao funcionamento da engrenagem verbal para o uso é por meio das tecnologias da informação e comunicação. Com efeito, as novas tecnologias podem ser grandes aliadas no desenvolvimento de práticas de ensino e aprendizagem que dão importância ao conceito de texto como "produções verbais efetivas, que assumem 
aspectos muito diversos, principalmente por serem articuladas a situações de comunicação muito diferentes" (BRONCKART, 2009, p. 69). Essa concepção baseia-se na ideia de que:

[...] embora toda língua natural pareça, de fato, estar baseada nas regras de um sistema, essas só podem ser identificadas e conceitualizadas por um procedimento de abstração-generalização, a partir de propriedades observáveis dos diversos textos utilizados em uma comunidade (BRONCKART, 2009, p. 69).

Nesse sentido, acreditamos que o uso de exercícios de correção automática que estimulem os estudantes a resgatarem seus conhecimentos prévios, propostos por meio de ambientes virtuais de aprendizagem, como o Moodle ou o Blackboard, por exemplo, podem facilitar o processo de ensino e aprendizagem das funções das estruturas gramaticais em uso nos textos. A ideia é que essas atividades levem os aprendizes a refletirem sobre os usos da língua para que depois esses usos sejam sistematizados em aula e fixados por meio de outros exercícios, incluindo práticas de escrita.

É certo que esses mesmos exercícios preliminares poderiam ser aplicados em sala de aula, mas a vantagem do uso de ambientes virtuais de aprendizagem é que os estudantes, quando interagem com a máquina, estão interagindo consigo mesmos, resgatando verdadeiramente seus conhecimentos prévios. Em sala, é natural que haja intervenções externas do professor e de outros estudantes que podem interferir no processo de autoavaliação dos conhecimentos prévios do aprendiz.
Sendo assim, este trabalho propõe-se a apresentar um exercício de leitura que busca, por meio da prática interativa entre o estudante e o texto, propiciar a reflexão sobre o papel das estruturas contrastivas no processo de argumentação, bem como a sistematização do uso dessas estruturas. O exercício procura mobilizar os conhecimentos prévios do aprendiz para que ele possa compreender a dinâmica dos articuladores na construção de estratégias argumentativas. Acreditamos que, desse modo, o conteúdo possa ser internalizado e sistematizado pelo estudante de modo mais eficiente e duradouro, uma vez que não será construído a partir de informações exteriores, mas como produto da subjetividade do aprendiz, assim como é a linguagem. Além disso, estamos convencidos de que essas estruturas gramaticais podem levar a conclusões sobre os fenômenos de ordem discursivas do texto e sensibilizar o estudante para a coerência que se estabelece entre como se diz e aquilo que se pretende dizer.

Para tanto, o trabalho será dividido em três seções. Na primeira, discutiremos o problema que motivou a pesquisa: as práticas de leitura e escrita, a argumentação e a importância do uso de conectores nessa modalidade. Na segunda, trataremos de um aspecto específico dos estudos argumentativos: o uso de conectores, e, mais especificamente, das estruturas contrastivas, adversativas e concessivas, e de seu papel na construção dos sentidos em uma crônica de Lima Barreto, Queixa de defunto. Faremos isso de forma prática, 
descrevendo o percurso de leitura desenvolvido para dar base à reflexão sobre a articulação de ideias de adversidade e de concessão. Na terceira seção, por fim, apresentaremos uma atividade de resgate de conhecimentos prévios cujo objetivo é auxiliar o aprendiz a compreender as estratégias argumentativas construídas por meio do uso dessas estruturas contrastivas. Essa compreensão objetiva, simultaneamente, desenvolver as competências leitora e escritora para que $o$ aprendiz possa construir posteriormente suas próprias argumentações.

Por fim, cabe esclarecer que o uso específico do fenômeno das estruturas contrastivas serve, em nosso trabalho, como exemplo do método que pode ser aplicado a outros fenômenos linguísticos. Este, especificamente, foi escolhido pelo fato de envolver conjunções ou estruturas gramaticais que cumprem funções parecidas, de estabelecer contraste entre ideias, mas não equivalentes. Além disso, o domínio completo da língua, que garante um competente registro escrito das ideias, pressupõe o domínio das formas de articulação dos elementos que compõem os enunciados na linearidade textual.

\section{Práticas de leitura e escrita: conectores e orientação argumentativa}

A produção de um texto, seja oral seja escrita, tem estreita relação com o querer dizer do locutor (KOCH, 2015), assim como a leitura tem a ver com os objetivos do leitor (Schnotz, 2009). Ler implica, por parte do leitor, uma intenção de compreensão para satisfazer outra intenção mais específica, ligada à finalidade para a qual se realiza a leitura. Desse ponto de vista, compreendemos que a leitura envolve uma interação entre o leitor e o texto. O leitor procura identificar o efeito pretendido pelo produtor do texto, sua intenção, e, portanto, a orientação argumentativa. O processo de compreensão, segundo Schnotz (2009, p. 169), constitui uma tentativa, por parte do leitor, de comprender "o que autor quis dizer", inclui também o conhecimento gramatical, pois os textos "constituem-se de orações” (SCHNOTZ, 2009, p. 166).

No mesmo sentido, apoiando-se em Van Dijk (1997), para quem o estudo do texto deve partir do uso da linguagem para se chegar a dimensões comunicativas e interacionais, Cabral (2013) sugere que devemos iniciar pelo mais concretamente observável e superficial, para se chegar ao sentido. O leitor usa seus conhecimentos de ordem linguística e gerais para compreender um texto, na tentativa de identificar, por conjectura, as intenções do produtor do texto. Este, por sua vez, também utiliza seus conhecimentos para expressar seu querer dizer.

Pode-se afirmar que o hiato entre a intenção e a expressão tenderá a tornar-se menor, em textos escritos, quando elementos linguísticos como os conectores sejam utilizados adequadamente. Charolles (1978) ensina que impossibilidade de unir duas frases por um conector cons- 
titui uma prova de incongruência, o que evidencia sua importância para deixar clara a relação pretendida pelo produtor do texto. A importância dos conectores para a práticas de escrita é também destacada por Bronckart (2009); esse autor lembra que a função do conector não é ornamentar o texto, nem apenas organizá-lo, mas sobretudo permitir o acesso a informações necessárias às inferências. Os postulados desses autores indicam a importância de se trabalhar o uso dos conectores que marcam o contraste, pois eles são os responsáveis por indicar caminhos de leitura que desfazem uma possível contradição. Acreditamos que sensibilizar os estudantes por meio de leituras que permitam exemplificar usos significativos dos conectores pode ser uma estratégia para lhes fornecer conhecimentos relativos às ferramentas linguísticas para a produção de textos em geral e de caráter argumentativo especificamente. $\mathrm{O}$ valor de certas expressões em determinados contextos, bem como o emprego dos conectores que:

[...] constituem estratégias linguísticas de argumentação e, por esse motivo, são importantes instrumentos para a produção de textos, uma vez que nossas escolhas linguísticas determinam a maior ou menor força argumentativa de nossos discursos (CABRAL, 2010, p. 140).

Uma perspectiva enunciativa dos processos de produção de textos escritos contempla o fato de que a utilização da linguagem, como já afirmou Amossy (2013), comporta sempre uma dimensão argumentativa, pois sempre se trans- mite um ponto de vista sobre as coisas, o que se marca, entre outros, pelos elementos de conexão.

Gaonac'h e Fayol (2003), por exemplo, em obra dedicada à compreensão em ambientes virtuais, ressaltam que a compreensão não se satisfaz com a construção de representações fragmentárias justapostas; ela exige uma organização que lhe confira unidade e coerência, o que, a nosso ver, implica a utilização de marcadores de conexão. Devemos considerar que os postulados desses autores relativamente à leitura são válidos igualmente para a escrita. Adam (2011) mesmo ressalta as complexas funções que desempenham os conectores em um texto, permitindo observar tanto o nível da textura, como o semântico e o da enunciação, incluindo a orientação argumentativa.

Dada a importância dos conectores, um dos grandes problemas que o professor enfrenta no desenvolvimento do processo de ensino e aprendizagem da leitura e da escrita está ligado à dificuldade do estudante na tarefa de articular as ideias. Muitas vezes, o aprendiz tem razoável conhecimento sobre os temas e consegue verbalizar pensamentos com certa desenvoltura, mas, na hora de registrá-los por escrito, em textos argumentativos, faltam-lhe os conectores adequados para a articulação desses pensamentos. A fala admite reticências, repetições de palavras, auxílio de gestos e o preenchimento de lacunas por meio do diálogo com o interlocutor: 
[...] na língua falada ou escrita, quando se traduzem situações simples, a interrelação entre as ideias pode prescindir das partículas conetivas mais comuns [...] o liame entre orações e períodos muitas vezes se faz implicitamente, sem a interferência desses conectivos: uma pausa adequada, uma entonação de voz podem ser suficientes para interrelacionar ideias (GARCIA, 1986, p. 278).

$O$ registro escrito, todavia, exige um maior rigor formal, não dá espaço para questionamentos e qualquer conexão inadequada pode contribuir para a incoerência do texto, trair a intenção de dizer do produtor.

Conectores são palavras ou expressões que ligam, articulam, promovem a transição entre palavras, frases, orações, períodos, parágrafos. Entre esses conectores, estão as conjunções, especialmente valiosas no que diz respeito à conexão de ideias mais complexas, uma vez que "são os vocábulos gramaticais que servem para relacionar duas orações ou dois termos semelhantes da mesma oração" (CUNHA; CINTRA, 1985, p. 565). As conjunções podem ser coordenativas quando "relacionam termos ou orações de idêntica função gramatical" ou subordinativas quando "ligam duas orações, uma das quais determina ou completa o sentido da outra" (CUNHA; CINTRA, 1985, p. 565).

Embora tenhamos um pequeno número de conjunções na língua, não basta que o estudante decore uma lista delas e seus respectivos significados para que seja bem sucedido na tarefa de usá-las como articuladores de ideias. Os sentidos desses termos variam assim como valor dos números nas expressões matemáticas, que possuem valores absolutos e posicionais, de acordo com o lugar da expressão em que se inserem. O número 1 , por exemplo, pode valer uma unidade quando está sozinho, mas à frente de um zero passa a valer uma dezena, à frente de dois zeros passa a valer uma centena, e assim por diante.

\section{Estudo das estruturas contrastivas no texto "Queixa de defunto", de Lima Barreto}

Acreditamos que apenas explicações teóricas dos fenômenos linguísticos em sala de aula são pouco produtivas, ao passo que a observação deles em textos cria situações de aprendizagem mais significativas. Também acreditamos que a aprendizagem torna-se mais significativa quando procura atingir objetivos específicos. Nunca poderíamos explorar, em uma situação de aprendizagem, todos os fenômenos linguísticos de um texto complexo. Também não seria adequado trabalhar com fragmentos, haja vista nossa necessidade de apresentar um material linguístico que tenha unidade de sentido e que possa ser estudado sob as perspectivas enunciativa e discursiva da linguagem.

Sendo assim, como proposta para uma situação de aprendizagem que envolve prática de leitura, selecionamos a crônica de Lima Barreto Queixa de 
defunto. Acreditamos que a qualidade do texto, sua leveza, a simplicidade vocabular e a temática sejam elementos que contribuem para atrair a atenção do aprendiz para a atividade, tornando-a mais lúdica. Outro motivo da escolha do texto foi, justamente, o caráter argumentativo do material linguístico, caracterizado, entre outras coisas, pelo manejo preciso dos conectores.

Entre outros conectores, chamou-nos a atenção, na crônica, o uso das estruturas contrastivas indicadoras de adversidade, "mas", "e não" e "porém"; e as indicadoras de concessão: "embora", "conquanto" e "apesar de".

Nesta seção, faremos um estudo do comportamento desses conectores com a finalidade de dar embasamento teórico para o desenvolvimento de uma atividade de correção automática (que apresentaremos da seção 3 deste trabalho) que permita o resgate dos conhecimentos prévios dos aprendizes a respeito do uso das estruturas contrastivas para posterior discussão em sala de aula.

\section{Queixa de defunto}

Lima Barreto

1. Antônio da Conceição, natural desta cidade, residente que foi em vida, na Boca do Mato, no Méier, onde acaba de morrer, por meios que não posso tomar público, mandou-me a carta abaixo que é endereçada ao prefeito. Ei-la:

2. Ilustríssimo e Excelentíssimo Senhor Doutor Prefeito do Distrito Federal.
Sou um pobre homem que em vida nunca deu trabalho às autoridades públicas nem a elas fez reclamação alguma. Nunca exerci ou pretendi exercer isso que sé chama os direitos sagrados de cidadão. Nasci, vivi e morri modestamente, julgando sempre que o meu único dever era ser lustrador de móveis e admitir que os outros os tivessem para eu lustrar e eu não.

3. Não fui republicano, não fui florianista, não fui custodista, não fui hermista, não me meti em greves, nem coisa alguma de reivindicações e revoltas, mas morri na santa paz do Senhor quase sem pecados e sem agonia.

4. Toda a minha vida de privações e necessidades era guiada pela esperança de gozar depois de minha morte no sossego, uma calma de vida que não sou capaz de descrever, mas que pressenti pelo pensamento, graças à doutrinação das seções católicas dos jornais.

5. Nunca fui ao espiritismo, nunca fui aos "bíblias", nem a feiticeiros, e apesar de ter tido um filho que penou dez anos nas mãos dos médicos, nunca procurei macumbeiros nem médiuns.

6. Vivi uma vida santa e obedecendo às prédicas do Padre André do Santuário do Sagrado Coração de Maria, em Todos os Santos, conquanto as não entendesse bem por serem pronunciadas com toda a eloquência em galego ou vasconço. 
7. "Segui-as, porém, com todo o rigor e humildade, e esperava gozar da mais dúlcida paz depois de minha morte. Morri afinal um dia destes. Não descrevo as cerimônias porque são muito conhecidas e os meus parentes e amigos deixaram-me sinceramente porque eu não deixava dinheiro algum. É bom meu caro Senhor Doutor Prefeito, viver na pobreza, mas muito melhor é morrer nela. Não se levam para a cova maldições dos parentes e amigos deserdados; só carregamos lamentações e bênçãos daqueles a quem não pagamos mais a casa.

8. Foi o que aconteceu comigo e estava certo de ir direitinho para o Céu, quando, por culpa do Senhor e da Repartição que o Senhor dirige, tive que ir para o inferno penar alguns anos ainda.

9. Embora a pena seja leve, eu me amolei, por não ter contribuído para ela de forma alguma. A culpa é da Prefeitura Municipal do Rio de Janeiro que não cumpre os seus deveres, calçando convenientemente as ruas. Vamos ver por quê. Tendo sido enterrado no cemitério de Inhaúma e vindo o meu enterro do Méier, o coche e o acompanhamento tiveram que atravessar em toda a extensão a rua José Bonifácio, em Todos os Santos.

10. Esta rua foi calçada há perto de cinquenta anos a macadame e nunca mais foi o seu calçamento substituído. Há caldeirões de todas as profundidades e largura, por ela afora.
Dessa forma, um pobre defunto que vai dentro do caixão em cima de um coche que por ela rola, sofre o diabo. De uma feita um até, após um trambolhão do carro mortuário, saltou do esquife, vivinho da silva, tendo ressuscitado com o susto.

11. Comigo não aconteceu isso, mas o balanço violento do coche, machucou-me muito e cheguei diante de São Pedro cheio de arranhaduras pelo corpo. O bom do velho santo interpelou-me logo:

12. - Que diabo é isto? Você está todo machucado! Tinham-me dito que você era bem comportado - como é então que você arranjou isso? Brigou depois de morto?

13. Expliquei-lhe, mas não me quis atender e mandou que me fosse purificar um pouco no inferno.

14. Está aí como, meu caro Senhor Doutor Prefeito, ainda estou penando por sua culpa, embora tenha tido vida a mais santa possível. Sou, etc., etc.

15. Posso garantir a fidelidade da cópia e aguardar com paciência as providências da municipalidade.

Careta, 20-3-1920

BARRETO (2015)

Numa primeira leitura, isolamos as estruturas adversativas e concessivas. As estruturas adversativas encontradas no texto foram: "mas", no terceiro, quarto, sétimo, décimo primeiro e décimo terceiro parágrafos; "porém”, no sétimo parágrafo; e, apresentada por meio de 
uma construção especial, a locução composta de uma aditiva e de um advérbio de negação, na última linha do segundo parágrafo: "e [eu] não". Esse uso especial da aditiva combinada com o advérbio de negação que assume valor adversativo sensibiliza o estudante para o fato de que a simples classificação gramatical dos termos pode ser improdutiva quando se busca o sentido do texto. A sensibilização para esse processo será, portanto, objeto de um exercício de resgate de conhecimentos prévios dos aprendizes.

As estruturas concessivas encontradas na crônica foram: as tradicionais conjunções "embora", parágrafos nove e catorze; a pouco utilizada conjunção "conquanto", parágrafo três; e a oração reduzida de infinitivo concessiva, "apesar de ter", parágrafo cinco.

$\mathrm{O}$ interesse pelo estudo dessas estruturas dá-se pelo fato de que, embora ambas expressem ideias de oposição, contraste ou contrariedade, elas não podem ser intercambiadas sem que o sentido do texto se altere. A adversativa liga dois termos ou orações que têm semelhante função sintática, mas acrescenta-lhes uma ideia de contraste (CUNHA; CINTRA, 1985, p. 565). Já a concessiva, inicia "uma oração subordinada em que se admite um fato contrário à oração principal, mas incapaz de impedi-la” (CUNHA; CINTRA, 1985, p. 572). Vale dizer, que as estruturas adversativas aparecem em períodos coordenados enquanto as concessivas aparecem em períodos subordinados.
Quanto mais preciso for o uso dos conectores de adversidade e concessão, mais lógicos serão os argumentos e mais qualidade terão, pois:

Do ponto de vista semântico, as orações concessivas têm sido aproximadas das orações coordenadas adversativas [...], uma vez que ambas referem uma circunstância que se opõe ou contrasta com a da oração principal. As frases com orações concessivas têm, no entanto, propriedades distintas das frases com orações adversativas, não só no que diz respeito à maneira como a informação é apresentada, como também à relação sintática que se estabelece entre as duas orações conectadas (LOBO, 2013, p. 2.017).

As ocorrências das adversativas na crônica permitem que se ilustrem certas propriedades delas.

(1) Nasci, vivi e morri modestamente, julgando sempre que o meu único dever era ser lustrador de móveis e admitir que os outros os tivessem para eu lustrar e eu não.

(2) Não fui republicano, não fui florianista, não fui custodista, não fui hermista, não me meti em greves, nem coisa alguma de reivindicações e revoltas, mas morri na santa paz do Senhor quase sem pecados e sem agonia.

(3) Toda a minha vida de privações e necessidades era guiada pela esperança de gozar depois de minha morte no sossego, uma calma de vida que não sou capaz de descrever, mas que pressenti pelo pensamento, graças à doutrinação das seções católicas dos jornais.

(4) Vivi uma vida santa e obedecendo às prédicas do Padre André do Santu- 
ário do Sagrado Coração de Maria, em Todos os Santos, conquanto as não entendesse bem por serem pronunciadas com toda a eloquência em galego ou vasconço.

(5) Segui-as, porém, com todo o rigor e humildade, e esperava gozar da mais dúlcida paz depois de minha morte.

(6) É bom meu caro Senhor Doutor Prefeito, viver na pobreza, mas muito melhor é morrer nela.

(7) Comigo não aconteceu isso, mas o balanço violento do coche, machucou-me muito e cheguei diante de São Pedro cheio de arranhaduras pelo corpo.

(8) Expliquei-lhe, mas não me quis atender e mandou que me fosse purificar um pouco no inferno.

Em (1) e (7), percebe-se que, para além do valor adversativo, encontramos aquilo que Matos e Raposo chamam de

[...] valores adicionais da conjunção adversativa, mas: [...] coordenação adversativa

focalizadora (cf. convidamos o Antônio mas não o João), delimitação de foco (cf. a Maria vai mas é ao cinema) e repetição enfática (cf. essa criança corre, mas corre (muito) (2013, p. 1.801, grifos dos autores).

Enquanto a delimitação de foco ocorre na linguagem coloquial e a repetição enfática em usos estilisticamente marcados, a coordenação adversativa focalizadora confere um valor adicional à ideia de adversidade pelo fato de os termos coordenados serem "sintagmas nominais ou preposicionais, um deles marcado pelo operador negativo não e podendo o outro ser modificado pelo operador afirmativo sim" (2013, p. 1.802). Em (1) também é necessário notar que a ideia de adversidade constrói-se sem o uso da conjunção adversativa, mas por meio da aditiva e do operador negativo (e não).

As interpretações são representadas em (1a) e (7a):

(1a) Nasci, vivi e morri modestamente, julgando sempre que o meu único dever era ser lustrador de móveis e admitir que os outros os tivessem para eu lustrar mas eu não os tivesse.

(7a) Expliquei-lhe, mas não me quis atender e mandou que me fosse purificar um pouco no inferno.

Especialmente em (1), o efeito de sentido que se obtém do uso da estrutura "e não" é o sentimento de conformidade do sujeito com o fato de ele não ter bens enquanto os outros têm, pois a falta de bens desse homem modesto, se do ponto de vista sintático contrasta com a posse alheia, do ponto de vista semântico é fator que aumenta a modéstia, argumento que o autorizaria a ir direto para o céu depois de morto.

Isso justifica o uso do valor adicional da adversativa focalizadora em (7), já que as explicações dadas ao santo deveriam tê-lo convencido a deixar o sujeito ir para o céu, mas não foi o que aconteceu. $\mathrm{O}$ efeito de sentido que se obtém do uso do operador negativo, neste caso, é a maior ênfase dada à injustiça feita já que ela vem de quem menos se espera: São Pedro. 
Outro fato linguístico relevante é o uso do "porém" em (4). Embora esse conector seja classificado como conjunção adversativa, Matos e Raposo apontam que eles:

[...] têm o comportamento típico dos adjuntos adverbiais periféricos [...] (i) podem ocorrer no início de uma oração [...], entre sujeito e predicado; (ii) formam, por si próprios, um domínio prosódico e entoacional, assinalado na escrita por vírgulas, com pausas possíveis de um lado e de outro. Para além disso, podem ocorrer noutros contextos, não apenas em estruturas de coordenação (2013, p. 1.809).

No caso específico da crônica de Lima Barreto, o uso do termo "porém" em (4) apresenta, para além do valor contrastivo, uma propriedade próxima de uma locução adverbial, bem como certo valor conclusivo já que introduz o último de uma série de argumentos que justificariam o mérito do sujeito de ir para o céu pelas ações que fez em vida. Vale observar que, imediatamente após enumerar essa última razão, o sujeito começa a falar de sua morte: "Morri afinal um dia destes". Note, ainda, que a proximidade do conectivo "porém" ao advérbio "afinal" reforça a interpretação que podemos dar a (4) em (4a).

(4a) Vivi uma vida santa e obedecendo às prédicas do Padre André do Santuário do Sagrado Coração de Maria, em Todos os Santos, conquanto as não entendesse bem por serem pronunciadas com toda a eloquência em galego ou vasconço.

Segui-as, finalmente, com todo o rigor e humildade, e esperava gozar da mais dúlcida paz depois de minha morte.

Além desses aspectos que podem mostrar ao aprendiz como as classificações de palavras e termos podem ser revistas quando as estruturas forem mostradas no contexto, podemos ainda perceber que os processos de coordenação não se ligam somente à conexão das ideias. A subordinação sintática também se estende, em certo sentido, para a organização dos níveis temporais dos fragmentos articulados. Podemos notar que em todas essas estruturas, que são coordenadas, os fatos que se opõem não são anteriores uns aos outros: os outros tinham móveis para lustrar, mas o sujeito não tinha, em (1); não foi uma série de coisas, mas morreu, em (2); a vida era guiada pela esperança que não é capaz de descrever, em (3) subentende-se que durante toda a vida, o sujeito não foi capaz de descrever a esperança e depois de morto ainda não é, mas pressentiu-a; o sujeito não entendeu as prédicas, porém as seguiu, em (4); é bom viver, mas é bom morrer, ambas as ações no presente, em (5); não aconteceu (a queda do sujeito), mas machucou-se, em (6); e explicou, mas o santo não quis atender, em (7). Podemos dizer que o valor sintático equivalente que as estruturas apresentam se completam também por meio do aspecto temporal que as une.

Já as estruturas concessivas, que são subordinadas, articulam fatos anteriores a outros que são posteriores:

(1) Nunca fui ao espiritismo, nunca fui aos 'bíblias', nem a feiticeiros, e apesar de ter tido um filho que penou dez anos nas mãos dos médicos, nunca procurei macumbeiros nem médiuns. 
(2) Vivi uma vida santa e obedecendo às prédicas do Padre André do Santuário do Sagrado Coração de Maria, em Todos os Santos, conquanto as não entendesse bem por serem pronunciadas com toda a eloquência em galego ou vasconço.

(3) Embora a pena [dada] seja leve, eu me amolei, por não ter contribuído para ela de forma alguma.

(4) Está aí como, meu caro Senhor Doutor Prefeito, ainda estou penando por sua culpa, embora tenha tido vida a mais santa possível.

A subordinação sintática, por assim dizer, estende-se para a subordinação temporal. Em (8), o fato anterior de ter tido um filho doente poderia servir como justificativa para que o sujeito abandonasse posteriormente sua religião, coisa que ele não fez. Em (9), o fato anterior, de não entender as prédicas, poderia ser justificativa para que ele não as obedecesse posteriormente, contudo ele continuou obedecendo-as. Em (10), o fato anterior, de a pena dada pelo santo ter sido leve, seria justificativa para ele não se amolar, contudo amolou-se posteriormente. Em (11), o fato anterior de ter tido uma vida santa, poderia justificar a remissão da pena, contudo isso não aconteceu. Podemos dizer que todas as orações subordinadas, nesse caso, expressam fatos passados que só podem ser convenientemente avaliados se confrontados com fatos anteriores: o valor de não abandonar a religião torna-se mais significativo diante da doença do filho; o valor de seguir as prédicas torna-se mais significativo frente ao fato de não entendê-las; a indignação do sujeito frente à pena leve justifica-se pelo fato de ele não merecer pena alguma; a tragédia de ter sido condenado torna-se maior frente ao fato de ter tido uma vida santa.

Do confronto entre as duas estruturas, podemos considerar que a adversidade implica a expressão de realidades que se opõem e são expressas pelo sujeito mais com a intenção de constatar o contraste do que de combatê-lo. Dentro da argumentação, o lugar em que ocupam revelam a aceitação dos contrastes apresentados entre as realidades articuladas do modo mais pacífico pelo sujeito que produz o discurso. Essa passividade, contudo, apresenta diferentes graus de acordo com o contexto, como vimos na análise de (1) um sujeito vivo mais conformado com a privação do corpo e (7) um sujeito morto mais indignado com o castigo da alma.

Já a concessão, apresenta a articulação de realidades opostas percebidas pelos sujeitos de modo menos pacífico. Não é à toa que, na crônica de Lima Barreto, o defunto usa as estruturas adversativas ao elencar acontecimentos dos quais não teve como escapar ou com os quais não se revoltou, pelo menos naquele momento. Já quando se serve das estruturas concessivas, é para expressar sua indignação com a realidade contrária à que esperava - a pena no inferno - em contraste com a que merecia, uma vida no paraíso. Nesse sentido, o ápice do 
processo argumentativo dá-se em (10), em que se revela a revolta do sujeito, sua amolação; e em (11), em que acusa formalmente o gestor público como responsável pela injustiça que sofreu.

Essa leitura nos permite constatar que, embora ambas as estruturas sejam contrastivas, a concessiva revela-se, via de regra, mais enfática do que a adversativa. Isso está de acordo com o fato de a concessiva articular fatos ocorridos no passado distante contrários aos fatos que se constata no presente ou foram constatados num passado mais próximo. Aqueles, tendo a força de impedir estes, que são indesejáveis no caso do texto, não conseguiram fazer isso.

Acreditamos que a sensibilidade para a percepção desses fatos pelo aprendiz não está ligada, necessariamente, aos conhecimentos gramaticais que ele tenha. Pensamos que, quando apresentamos esses fatos linguísticos no texto, por serem fenômenos que se fazem perceptíveis no processo de enunciação em função do objetivo enunciativo do material linguístico, isso sensibilizará o estudante para a percepção no ato da leitura, e futura utilização no ato da escrita, dessas estratégias enunciativas ligadas ao uso dos conectivos. Desse modo, a proposta de atividade que apresentaremos a seguir pretende ser um instrumento para que o aprendiz, indutivamente, chegue às conclusões a que chegamos por meio da análise das estruturas contrastivas.
Proposta de atividade de correção automática em ambiente virtual de aprendizagem: resgatando conhecimentos prévios dos estudantes sobre $o$ uso dos conectores

Marty (2005) afirma que o leitor de ambientes tecnológicos orienta a construção dos sentidos a partir das ferramentas e do suporte de que ele dispõe e a partir dos conteúdos que lhe propõe o produtor. Esses conteúdos incluem, evidentemente, as marcas linguísticas da superfície textual, o que nos remete a Le NY (2005), para quem, em primeiro lugar, o leitor percebe a estrutura do texto, reconhecendo as categorias prototípicas do material que tem em mãos. Entre as estruturas textuais encontram-se evidentemente as estruturas dos enunciados na linearidade da superfície textual; a esse respeito, retomamos Coirier, Gaonac'h e Passerault (1996), que incluem, entre os processos que atuam na produção escrita, de forma integrada, as determinações ligadas ao sistema da língua, e, mais especificamente a explicitação dessa estrutura por conectores, foco da atividade que apresentamos a seguir, a título de exemplificação.

Nossa proposta contempla atividade de correção automática realizada em ambiente virtual de aprendizagem, como o Moodle ou o Blackboard. Essa atividade 
baseia-se no uso de marcadores coesivos e organizadores textuais, notadamente os contrastivos, adversativos e concessivos os quais, como vimos, são articuladores fundamentais para a orientação argumentativa. Além disso, o exercício permite ao estudante verificar se sua resposta está correta ou não e apresenta, no gabarito, uma breve explicação justificando a resposta correta para que ele tome consciência a respeito da adequação ou não de seus conhecimentos sobre o tópico a ser estudado.

Vale, no entanto, lembrar que a atividade de correção automática constitui apenas o passo inicial do trabalho, quando o estudante é confrontado com os seus conhecimentos prévios relativos ao conteúdo, que deverá ser aprofundado, presencialmente, com o professor, mediante discussão, inclusive sobre as respostas não corretas e os motivos pelos quais o estudante errou ao responder. Essa discussão enseja a reflexão sobre as especificidades dos fenômenos em estudo que foram apresentadas anteriormente no subitem Estudo das estruturas contrastivas no texto "Queixa de defunto", de Lima Barreto.

Apresentamos a seguir, no Quadro 1, a atividade de correção automática proposta a partir da leitura da crônica de Lima Barreto que tem como finalidade resgatar conhecimentos prévios e dar início à discussão sobre os aspectos pertinentes às estruturas contrastivas que levantamos na seção 2 deste trabalho.

Antes de o estudante realizar a atividade, é necessário assegurar que ele tenha lido o texto. Isso seria feito no ambiente virtual de aprendizagem por meio de um enunciado que solicite a leitura da crônica Queixa de defunto e que apresente o texto para o aprendiz. Além disso, nesse enunciado é necessário acrescentar uma paráfrase da crônica em que se ressalte que o protagonista é um defunto, que nunca exerceu ou pretendeu exercer os direitos sagrados de cidadão resignando-se ao longo da existência, e que agora se revela queixoso perante o prefeito de sua comunidade, exercendo, depois de morto, a cidadania que deveria ter sido exercida em vida. Também é necessário ressaltar que no processo argumentativo que justifica a mudança de atitude do sujeito, o defunto apresenta várias razões culminando na culpabilidade do prefeito pelo fato de ter ido para o inferno já que deveria, após sua morte, ter sido encaminhado ao céu. $O$ defunto constata, ainda, que essa injustiça ocorreu por conta do descaso do poder público na conservação do calçamento, fato que o fez chegar ao céu tão machucado que São Pedro julgou que ele só poderia ser má pessoa e o enviou ao inferno.

Somente depois da leitura do texto, solicita-se ao aprendiz que faça a atividade de correção automática dada a seguir. Para isso, cria-se uma ligação, abaixo da crônica e da resenha, para o enunciado que apresenta oito excertos da crônica e cinco considerações em torno desses excertos, sendo apenas uma dessas considerações correta. 
Quadro 1 - Proposta de atividade em ambiente virtual de aprendizagem

Leia com atenção os seguintes trechos retirados da crônica Queixa de defunto, de Lima Barreto, e escolha a alternativa que analisa o uso dos conectores de maneira correta.

I - "Nasci, vivi e morri modestamente, julgando sempre que o meu único dever era ser lustrador de móveis e admitir que os outros os tivessem para eu lustrar e eu não.

II - "Nunca fui ao espiritismo, nunca fui aos 'bíblias', nem a feiticeiros, e apesar de ter tido um filho que penou dez anos nas mãos dos médicos, nunca procurei macumbeiros nem médiuns.

III - "Embora a pena seja leve, eu me amolei, por não ter contribuído para ela de forma alguma. A culpa é da Prefeitura Municipal do Rio de Janeiro que não cumpre os seus deveres, calçando convenientemente as ruas.

IV - Vivi uma vida santa e obedecendo às prédicas do Padre André do Santuário do Sagrado Coração de Maria, em Todos os Santos, conquanto as não entendesse bem por serem pronunciadas com toda a eloquência em galego ou vasconço.

V- Segui-as [as prédicas do Padre André do Santuário do Sagrado Coração de Maria que eu não entendia bem], porém, com todo o rigor e humildade, e esperava gozar da mais dúlcida paz depois de minha morte.

VI - É bom meu caro Senhor Doutor Prefeito, viver na pobreza, mas muito melhor é morrer nela. Não se levam para a cova maldições dos parentes e amigos deserdados; só carregamos lamentações e bênçãos daqueles a quem não pagamos mais a casa.

VII- O bom do velho santo interpelou-me logo:

"- Que diabo é isto? Você está todo machucado! Tinham-me dito que você era bem comportado - como é então que você arranjou isso? Brigou depois de morto?

"Expliquei-lhe, mas não me quis atender e mandou que me fosse purificar um pouco no inferno.

VIII - "Está aí como, meu caro Senhor Doutor Prefeito, ainda estou penando por sua culpa, embora tenha tido vida a mais santa possível. Sou, etc., etc."

a) Todos os trechos estabelecem relação de oposição entre os elementos que unem; em I, III e IV, o enunciado introduzido pelo conector apresenta um fato que ocorreu anteriormente ao fato que a ele se opõe.

b) Todos os trechos estabelecem relação de oposição entre os elementos que unem; em II, III, IV e VII, o enunciado introduzido pelo conector apresenta um fato que ocorreu anteriormente ao fato que a ele se opõe.

c) Todos os trechos estabelecem relação de oposição entre os elementos que unem; em II, III, IV e VIII, o enunciado introduzido pelo conector apresenta um fato que ocorreu anteriormente ao fato que a ele se opõe.

d) Todos os trechos estabelecem relação de oposição entre os elementos que unem; somente em II, V e VIII o enunciado introduzido pelo conector apresenta um fato que ocorreu anteriormente ao fato que a ele se opõe.

e) Todos os trechos estabelecem relação de oposição entre os elementos que unem; em I, II, IV e VI, o enunciado introduzido pelo conector apresenta um fato que ocorreu anteriormente ao fato que a ele se opõe.

Resposta correta: alternativa C

Justificativa: em II, o fato de ter tido um filho que penou dez anos nas mãos dos médicos é anterior a nunca procurar macumbeiros ou médiuns; em III o fato de a pena ser leve é anterior a eu me amolei; em IV o fato de não entender as prédicas é anterior ao fato de obedecê-las; em VIII, ter uma vida a mais santa possível é anterior ao fato de ele estar penando.

Fonte: elaborado pelos autores.

O objetivo dos enunciados apresentados é fazer os aprendizes notarem que os conectores, embora tenham aparentemente o mesmo valor argumentativo, nem sempre são intercambiáveis, pois na sua utilização entram em jogo outras questões, como as relações temporais que envolvem os fatos abordados, o emprego 
de tempos verbais, as construções nominais, apenas para citar alguns exemplos, atendo-nos ao contexto específico da atividade proposta.

Assim, por exemplo, ao abordar a questão da anterioridade dos fatos na construção argumentativa, pode-se também discutir a importância das intenções de dizer do produtor do texto, topicalizando determinado fato, dando maior ou menor destaque, conforme seus objetivos argumentativos, bem como realçando a intensidade da indignação com a injustiça sofrida. Essas discussões feitas em classe e fundamentadas pelo estudo apresentado na seção 2 deste trabalho podem ser ampliadas, posteriormente, na proposta de produção de texto de caráter argumentativo em que o estudante seja orientado a utilizar estruturas contrastivas na organização dos argumentos em favor de determinada tese.

\section{Considerações finais}

Cumpre observar que as questões abordadas na atividade serão estéreis caso não sejam retomadas em aula, momento em que será possível esclarecer as dúvidas dos estudantes, verificando com mais precisão os conhecimentos prévios de que eles dispõem e sistematizando esses conhecimentos. Essa proposta vem ao encontro de nossas observações iniciais sobre a precedência do fenômeno gramatical em relação à existência dele, o que vale dizer que, no caso presente, a ideia de conceder, da qual se extrai o nome das estruturas gramaticais concessivas, implica a ideia de que condições prévias favoráveis a determinado fato nem sempre garantem a efetivação dele na realidade. Isso significa que no cerne da ideia de concessão estão as condições necessárias, mas não suficientes para concretizar uma realidade indesejada pelo sujeito. É possível que por isso essa estrutura seja bastante usada em argumentos que, geralmente, introduzem descontentamento do sujeito em relação à realidade como se apresenta, por isso apoiam-se em contra-argumentos, fatos antecedentes que hipoteticamente não autorizariam essa realidade considerada inadequada que se impôs à revelia do sujeito. Isso ajuda a explicar por que esses conectores concessivos, geralmente, implicam o uso do subjuntivo ou de formas nominais (substantivos ou verbos na forma nominal).

Já as estruturas adversativas apresentam condições prévias que conduziriam a uma conclusão e que, de modo inapelável, apresentam conclusões opostas. Ainda que estranha, a realidade dos fatos não é decorrente de condições nem necessárias nem suficientes que os precederam e implica mais a constatação do que a contestação desses fatos. Dentro de uma estrutura argumentativa, essas oposições adversativas têm como função mais a construção inicial dos argumentos que a contestação de certo estado de coisas do que como elemento final, mais enfático, desses argumentos, função reservada à concessiva. De qualquer modo, essa constatação pode ser mais ou 
menos enfática dependendo da posição que ocupa no texto.

No texto em questão, pode-se dizer que o fato que mais causa espanto não é o sujeito estar penando no inferno por não ter merecido já que todas suas ações em vida apontavam para uma conclusão contrária a que a realidade mostra.

O que causa maior espanto e indignação do defunto e que motivou a denúncia à imprensa por meio de carta aberta é o fato de que, ao prefeito, merecedor de pena maior que a do defunto, seja aberta a concessão de ir direto para o céu, já que provavelmente seu corpo chegará ao outro mundo em bom estado físico. As estruturas mais profundas do texto nos revelam os contrastes entre aparência e essência, daí a pertinência do estudo das estruturas contrastivas do material.

Desse modo, ao se discutirem os sentidos do texto com ênfase nos possíveis empregos dos elementos de conexão e suas funções, reforça-se a distinção entre classificação gramatical e efeitos de sentido dos termos que expressam a orientação argumentativa. Não se trata de um estudo que visa à descrição da língua como uma ferramenta de comunicação, mas como uma estratégia de construção da subjetividade no processo de enunciação.

Desejamos oferecer aos estudantes possibilidades para que se tornem capazes, por um lado, de identificar as estratégias linguísticas passíveis de conferir forças argumentativas aos textos com os quais travam contato e, por outro, de dotar seus textos de força argumentativa compatível com suas intenções. Para tanto, o processo de reconhecimento das estratégias argumentativas utilizadas nos textos irá permitir que, de forma progressiva, controlada e conscientemente esses estudantes passem a utilizá-las em seus próprios textos. A nosso ver, nessa perspectiva, ensinamos Língua Portuguesa a nossos estudantes para que eles possam fazer uso adequado dela como forma de ação sobre o mundo tornando-se leitores críticos e produtores eficientes.

\section{Argumentation and} grammatical contrastive structures: practical activity of use of prior knowloledge using virtual learning environments

\section{Abstract}

This paper presents a practical activity of reading based on a chronicle of Lima Barreto, «Queixa de defunto», as a result of a linguistic research that allowed the construction of a significant learning situation focused on both the rescue of previous knowledge of students as on their awareness of different contrastive grammatical structures, adversative and concessive, so that they can understand, in practice, the difference and the function of these structures in the argumentative process. In this sense, the article presents a reading exercise which proposes the use of Virtual Learning Environments and seeks to mobilize the prior knowledge of the learner in order that he might be able to: understand the dynamics of the articulators in the construction of argumentative strategies; systematise and internalize this knowledge in a more efficient 
way. This teaching practice shows the importance of the connectors in the construction of texts written with competent argumentative orientation.

Keywords: Reading and writing. Argumentation. Grammar. New technologies and education.

\section{Referências}

ADAM, Jean-Michel. A linguística textual: introdução à análise textual dos discursos. 2. ed. rev. e aum. São Paulo: Cortez, 2011.

AMOSSY, Ruth. L'Argumentation dans le discours. Paris: Armand Colin, 2013.

BENVENISTE, Émile. Problemas de linguística geral I. 5. ed. Campinas: Pontes, 2005.

BRONCKART, Jean Paul. Atividades de linguagens, textos e discursos - por um interacionismo sociodiscursivo. 2. ed. São Paulo: Educ, 2009.

BARRETO, Lima. Queixa de defunto. Portal Domínio Público. Disponível em: <http:// www.dominiopublico.gov.br/download/texto/ bi000173.pdf>. Acessado em: 7 set. 2015.

CABRAL, Ana Lúcia Tinoco. A força das palavras. São Paulo: Contexto, 2010.

CABRAL, Ana Lúcia Tinoco. Plano de texto: estratégia para o planejamento da produção escrita. Revista Linha D’ Água, São Paulo, n. 26, p. 241-259, $2^{\circ}$ sem. 2013. Disponível em: <http://www.revistas.usp.br/linhadagua/ index >. Acesso em: 28 ago. 2015

CHAROLLES, MICHEL. Introduction aux problèmes de la coherence des textes. Pratiques, Paris: Larousse, n. 38, p. 7-41, 1978.

COIRIER, Pierre; GAONAC'H, Daniel; PASSERAULT, Jean-Michel. Psycholinguistique textuelle - une approche cognitive de la compréhension et de la production des texts. Paris: Armand Colin, 1996.
CUNHA, Celso; CINTRA, Luís F. Lindley. Nova gramática do português contemporâneo. 2. ed. Rio de Janeiro: Nova Fronteira, 1985.

GAONAC'H, Daniel; FAYOL, Michel. (Coord.) Aider les élèves à comprendre du texte au multimédia. Paris: Hachette, 2003.

GARCIA, Othon M. Comunicação em prosa moderna. 13. ed. Rio de Janeiro: FGV, 1986.

$\mathrm{KOCH}$, Ingedore Villaça. Introdução à linguística textual: trajetória e grandes temas. 2.ed. São Paulo: Contexto, 2015.

LE NY, Jean-François. Comment l'esprit produit du sens. Paris: Odile Jacob, 2005.

LYONS, John. Sémantique linguistique. Traduction de J. Durand e D. Baoulonnais. Paris: Larousse, 1990.

LOBO, Maria. Subordinação adverbial. In: RAPOSO, Eduardo Buzaglo Paiva et al. (Org.). Gramática do português. Lisboa: Fundação Calouste Gulbenkian, 2013. p. 1.981-2.057.

MARTY, Nicole. Informatique et nouvelles pratiques d'écritaure. Cahors: Nathan, 2005.

MATOS, Gabriela; RAPOSO, Eduardo Buzaglo Paiva. Estruturas de coordenação. In: RAPOSO, Eduardo Buzaglo Paiva et al. Gramática do português. Lisboa: Fundação Calouste Gulbenkian, 2013. p. 1.759-1.817.

SCHONTZ, Wolfgang. O que acontece na mente do leitor? Os processos de construção mentais durante a compreensão textual do ponto de vista psicológico e da linguística cognitiva. In: WEISSER, Hans Peter e KOCH, Ingedore G. Villaça (Org.) Linguística Textual: perspectivas alemãs. Rio de Janeiro, Nova Fronteira, 2009. p. 166-185.

VAN DIJK, Teun. Semântica do discurso e ideologia. In: PEDRO, Emília (Org.). Análise Crítica do Discurso: uma perspectiva sociopolítica e funcional. Lisboa: Caminho, 1997. p. 105-168. 